\title{
Strategi Pengembangan Wisata Tradisi Ojhung Berbasis Sport Tourism di Kabupaten Sumenep
}

Febryansah Gilang Aris Pradana ${ }^{a}$, Asha $^{b}$, Nurul Hidayatc, Dwi Lorry Juniariscad, Ali Imron ${ }^{\mathrm{e}}$

abcdeUniversitas Negeri Surabaya, Indonesia

Correspondence: febryansahpradana16060464058@mhs.unesa.ac.id

Received: 22 Jun 2019 Accepted: 13 Aug 2020 Published: 31 Oct 2020

\begin{abstract}
Sumenep Regency is known for its diverse cultures, one of which is Ojbung. Ojbung is the ritual performed as a request for rain. Ojbung is the art of fighting by hitting and fending off opponents using rattan guided by referees. Ojhung traditional art has the potential to be developed into cultural-based sport tourism, which combines sports activities with the strength of Ojbung traditional art. In line with the tourism sector which is the flagship in Sumenep. Evident from the inauguration of Sumenep as "Soul of Madura". This research aims to describe the development strategies of Ojbung tourism based on sport tourism in Sumenep Regency. This study used qualitative method. Data collection techniques in the form of observation, in-depth interviews, and literature studies. Data analyzed used SWOT, EFAS, and IFAS analysis. The data validity checking technique uses triangulation. Ojhung can be develop to be sport tourism in Sumenep Regency because it has a tourist attraction, based on the criteria among others: the ritual of request for rain and Ojbung competition, which visitors can participate in the Ojbung competition.
\end{abstract}

Keywords: ojbung; sport tourism; tourism development strategy

\begin{abstract}
Abstrak
Kabupaten Sumenep dikenal dengan kebudayaan yang beragam, salah satunya adalah Ojbung. Ojbung merupakan ritual yang dilakukan sebagai permohonan turunnya hujan. Ojbung adalah seni pertarungan dengan saling memukul dan menangkis lawan menggunakan rotan yang dipandu wasit. Seni tradisi Ojbung berpotensi dikembangkan menjadi wisata olahraga berbasis budaya, yakni menggabungkan kegiatan olahraga dengan kekuatan seni tradisi Ojbung. Sejalan dengan sektor pariwisata yang menjadi unggulan di Sumenep. Terbukti dari pengukuhan Sumenep sebagai "Soul of Madura". Penelitian ini bertujuan mendeskripsikan strategi pengembangan wisata tradisi Ojbung berbasis wisata olahraga di Kabupaten Sumenep. Penelitian ini menggunakan metode kualitatif. Data diperoleh melalui teknik pengumpulan data berupa observasi, wawancara, dan studi literatur. Data dianalisis dengan menggunakan analisis SWOT, EFAS dan IFAS. Teknik pemeriksaan keabsahan data menggunakan triangulasi. Ojbung dapat dikembangkan menjadi wisata olahraga di Kabupaten Sumenep karena memiliki daya tarik wisata, berdasarkan kriteria antara lain: adanya ritual memohon hujan dan pertandingan Ojhung, dimana pengunjung dapat berpartisipasi dalam pertandingan Ojbung.
\end{abstract}

Kata kunci: ojbung; wisata olahraga; strategi pengembangan wisata 


\section{Pendahuluan}

Sektor pariwisata ditetapkan sebagai sektor yang penting untuk dikembangkan secara sinergi sebagai sektor unggulan. Melalui pendekatan pariwisata berkelanjutan (sustainable tourism) diperlukan sinergi antara upaya pelestarian alam dan budaya beserta warisannya untuk menunjang percepatan pembangunan nasional (Astuti \& Noor, 2016). Dalam mewujudkan pembangunan pariwisata berkelanjutan pentingnya keterlibatan masyarakat lokal. Sebagaimana yang diungkapkan Albrecht (2010), bahwa keterlibatan masyarakat dalam perencanaan pariwisata ditentukan oleh persepsi masyarakat tersebut terhadap rencana pengembangan pariwisata itu sendiri, termasuk juga bagaimana potensi dampak ekonomi, sosial, dan lingkungannya terhadap mata pencaharian masyarakat. Begitu pula yang dilakukan di Kabupaten Sumenep Madura.

Pariwisata menjadi salah satu sektor unggulan di Sumenep. Mengutip dari (Cahyo, 2018) hal tersebut dibuktikan dengan meningkatnya angka kunjungan wisatawan selama dua tahun terakhir. Menurut data Pemerintah Kabupaten Sumenep, jumlah wisatawan yang berkunjung ke Kabupaten Sumenep pada 2016 mencapai 800 ribu orang. Pada tahun 2017, angka kunjungan naik 16 persen mencapai 1.049.000 wisatawan. Kabupaten Sumenep mengukuhkan diri sebagai "Soul of Madura", pada tahun 2018 mempersiapkan 36 even unggulan. Rangkaian acara tersebut diselenggarakan dalam satu tahun penuh berupa festival budaya, sejarah, olahraga, religi, dan kesehatan. Rangkaian acara tersebut dilakukan untuk mencapai target yang telah ditetapkan pemerintah Kabupaten Sumenep, yaitu minimal melampaui jumlah kunjungan pada tahun sebelumnya. Dalam rangka mengembangkan sektor pariwisata dan mencapai target pemerintah, diperlukan upaya membangun pariwisata berkelanjutan (Samiarta \& Mahagangga, 2016). Pembangunan pariwisata berkelanjutan merupakan proses pembangunan daerah tanpa mengurangi nilai guna dari suatu sumber daya yang sudah ada. Salah satunya dengan cara mengembangkan pariwisata alternatif. Menurut (Hani, 2007), pariwisata alternatif adalah kegiatan kepariwisataan yang tidak merusak lingkungan, menghindari dampak negatif dari pariwisata berskala besar yang dapat mengancam budaya daerah. Salah satu jenis pariwisata alternatif yang banyak mendapat perhatian saat ini adalah pariwisata olahraga (sport tourism).

Sport tourism adalah industri yang relatif baru dan terus meningkat dalam industri pariwisata yang berfokus pada target perencanaan di negara-negara berkembang (Honari, Goudarzi, Heidari, \& Emami, 2010). Sport tourism atau wisata olahraga merupakan jenis perjalanan untuk berpartisipasi dalam kegiatan olahraga, baik sekadar rekreasi, berkompetisi, maupun bepergian ke situs-situs olahraga seperti stadion (Di Palma, Tafuri, Ascione, \& Raiola, 2018). Sport Tourism dimaknai sebagai semua bentuk keterlibatan aktif dan pasif dalam kegiatan olahraga, berpartisipasi secara santai atau dengan cara yang teratur untuk alasan nonkomersial atau bisnis/komersial, yang mengharuskan perjalanan jauh dari rumah danwilayah kerja (Gibson, 2018). Secara umum terdapat tiga kategori yang luas dari wisata olahraga, menonton acara olahraga, mengunjungi tempat-tempat terkait olahraga, dan partisipasi aktif. Menurut (UU RI, 2005), menyebutkan bahwa olahraga rekreasi adalah olahraga yang dilakukan oleh masyarakat dengan kemauan dan kemampuan yang tumbuh dan berkembang sesuai dengan kondisi dan nilai budaya masyarakat setempat untuk kesehatan, kebugaran, dan kesenangan. Berdasarkan hal tersebut, olahraga dan pariwisata memiliki tujuan yang sama. Salah satu daerah yang memiliki peluang besar dalam pengembangan wisata olahraga (sport tourism) adalah Kabupaten Sumenep.

Kabupaten Sumenep berhasil meningkatkan sektor pariwisata melalui wisata alam yang menjadi unggulannya (Rosita, 2017). Selain itu, Kabupaten Sumenep Madura dikenal sebagai pulau yang memiliki kebudayaan berupa kesenian maupun tradisi adat yang beraneka ragam. Budaya ini secara turun-temurun dilestarikan hingga kini. Salah satunya di Desa Batu Putih Laok, Kecamatan Batu Putih, yaitu Ojhung. Ojhung merupakan ritual atau upacara adat yang dilakukan sebagai permohonan turun hujan tturunnya hujan (Prayoga, 2013), namun dengan seiring berjalannya waktu, seni Ojhung 
berkembang menjadi kesenian tradisional untuk acara hiburan dan permainan masyarakat. Sebagai sarana hiburan, kesenian Ojbung dipentaskan pada suatu acara misalnya pada acara melaksanakan nadzar dan selamatan desa atau sedekah bumi (Abbas, 2017). Permainan rakyat tradisional ini bersifat religius-magis. Unsur magis yang terdapat dalam budaya Ojhung ini yaitu adanya kekuatan supranatural yang dimiliki oleh para pemain Ojbung, karena Ojbung ini merupakan seni adu tarung, maka para pemain mengisi tubuh mereka dengan sebuah mantra agar tubuhnya memiliki sebuah kekebalan sehingga tidak akan mengalami luka-luka (Rahman, dkk., 2019). Tradisi pemanggil hujan Ojung terdapat mantra yang berjudul Bato' Peter. Frasa bato' peter terdiri atas kata bato' yang berarti 'batuk' dan kata peter yang berarti 'petir' (Maknuna, Mustamar dan Ningsih, 2013).

Ojhung merupakan seni pertarungan dengan saling memukul dan menangkis anggota badan lawan dengan menggunakan sebuah rotan yang dipimpin oleh wasit. Kesenian ini menonjolkan kekuatan fisik dari pemainnya. Kesenian Ojbung diiringi orkes Okol yang terdiri dari sebuah gambang dan dua tambur bercelah dari kayu atau biasa disebut dbuk-dhuk (Zulkarnain, 2004). Orkes Okol merupakan sekelompok pemain musik dengan seperangkat alat musik khas daerah pedalaman Kabupaten Sumenep yang biasanya digunakan sebagai pengiring dalam berbagai acara, seperti perlombaan merpati dan Ojbung.

Seni tradisi telah dikaji sebelumnya, seperti kajian (Anggita, Mukarromah, \& Ali, 2018), melihat seni tradisi dalam bentuk permainan tradisional yang tetap eksis sampai saat ini sebagai warisan budaya bangsa. Namun, sebagian besar permainan tradisional dan olahraga yang merupakan ekspresi budaya asli dan cara hidup yang memberikan kontribusi terhadap identitas umum kemanusiaan telah menghilang dan yang masih bertahan juga terancam hilang atau punah karena pengaruh globalisasi dan harmonisasi keragaman warisan olahraga dunia (Nur, 2013). Kondisi yang serupa juga dialami seni tradisi Ojhung. Untuk menghindari kepunahan, maka seni tradisi Ojbung harus terus dikembangkan, mengingat potensi yang terkandung di dalamnya.

Seni tradisi Ojbung memiliki potensi untuk dikembangkan menjadi sport tourism di Sumenep (Pradana, Hidayat, Juniarisca, \& Imron, 2019). Sport tourism yang akan dikembangkan berbasis budaya dengan memadukan olahraga dengan kekuatan seni tradisi Ojbung. Oleh karena itu, penelitian ini bertujuan mendeskripsikan seni tradisi Ojbung sebagai strategi pengembangan pariwisata berbasis sport tourism di Kabupaten Sumenep. Penelitian ini diharapkan dapat bermanfaat dalam mengembangkan wisata tradisi Ojbung berbasis sport tourism di Kabupaten Sumenep.

\section{Metode Penelitian}

Penelitian ini bersifat deskriptif yang bertujuan membuat deskripsi dari fenomena sosial secara sistematis, faktual, dan akurat (Wardiyanta, 2010). Penelitian ini menggunakan metode kualitatif yang dapat memberikan gambaran secara utuh dan menyeluruh tentang potensi seni tradisi Ojbung sebagai sport tourism dan strategi pengembangan wisata tradisi Ojbung berbasis sport tourism.

Penelitian ini mengambil lokasi di Desa Batu Putih Laok, Kecamatan Batu Putih, Kabupaten Sumenep karena hingga saat ini tradisi Ojhung masih dipertahankan. Informan penelitian ini antara lain Kepala Bidang Pembinaan Kesenian dan Tradisi, Dinas Kebudayaan, Pariwisata, Pemuda dan Olahraga Kabupaten Sumenep; Kepala Tourism Information Center Kabupaten Sumenep; Ketua Paguyuban Ojbung; dan pemain Ojbung, yang dipilih secara purposive.

Pengumpulan data dilakukan dengan dua cara, yaitu penggalian data primer dan data sekunder. Penggalian data primer dilakukan melalui observasi dan wawancara mendalam. Penggalian data sekunder dilakukan melalui penelusuran buku dan artikel ilmiah yang dipublikasikan dalam jurnal ilmiah nasional maupun internasional. 
Data yang diperoleh kemudian dianalisis menggunakan analisis SWOT. Data yang diperoleh sebelumnya dimasukkan dalam matriks EFAS (Eksternal Strategic Factor Analisis Summary) dan IFAS (Internal Strategic Factor Analisis Summary). Kemudian penyusunan matriks faktor strategi internal dan eksternal. Matriks faktor internal digunakan untuk mengetahui faktor-faktor yang mendukung seni tradisi Ojhung berpotensi menjadi sport tourism. Matriks faktor eksternal untuk mengetahui faktorfaktor peluang dan ancaman yang akan dihadapi. Hasil yang didapat dimasukkan dalam model kualitatif dengan menggunakan matriks SWOT untuk merumuskan strategi pengembangan pariwisata secara deskriptif. Penelitian ini menggunakan teknik triangulasi waktu pengumpulan data, triangulasi teknik pengumpulan data, dan triangulasi sumber data untuk menjamin validitas data (Sugiyono, 2010).

\section{Hasil}

Ojbung memiliki potensi berupa modal budaya (cultural capital) dan modal manusia (buman capital) untuk dijadikan destinasi wisata. Namun, memerlukan modal sosial (social capital) dan modal ekonomi (economic capital) yang besar. Menurut Godfrey and Clarke (dalam Sutawa, 2012), proses membentuk strategi pariwisata terdiri dari tiga langkah. Pertama, mengidentifikasi peluang dan kendala (berdasarkan evakuasi penawaran dan permintaan). Adapun peluang pengembangan Ojbung sebagai wisata berbasis sport tourism, antara lain pegiat Ojbung, termasuk pemerintahan desa memiliki keinginan yang kuat untuk mengembangkan Ojbung sebagai destinasi wisata. Ojbung memiliki potensi daya tarik wisata. Selain sebagai ritual turunnya hujan, Ojhung merupakan olahraga tradisional yang mengandung nilai sportivitas. Kuliner khas Sumenep juga menjadi peluang yang bisa dikembangkan untuk memperkuat economic capital masyarakat lokal untuk mendukung pengembangan wisata.

Sedangkan kendala yang dihadapi dalam pengembangan wisata berbasis sport tourism di Batuputih, Sumenep, antara lain dukungan anggaran, terutama APBD masih terbatas. Masyarakat Batuputih, termasuk pegiat Ojhung dinilai belum ada inisiatif untuk berkembang. Upaya yang dilakukan selama ini masih sebatas hanya agar Ojhung tidak punah. Di Batuputih juga belum ada homestay sebagai tempat tinggal wisatawan. Secara geografis, Batuputih letaknya kurang strategis karena berada di tengah perlintasan dari Bidaso ke Slopeng, sehingga jarang wisatawan yang singgah di Batuputih. Selain itu, ritual Ojbung hanya berlangsung ketika musim kemarau saja. Kedua, menetapkan tujuan dan sasaran pengembangan (mengatasi masalah yang membutuhkan perhatian dalam jangka pendek, menengah, dan panjang). Tujuan pengembangan wisata adalah mengembangkan seni tradisi Ojbung sebagai destinasi wisata berbasis sport tourism.

Ketiga, menetapkan serangkaian langkah tindakan (dirancang untuk mencapai tujuan dan target dalam jangka waktu tertentu). Adapun langkah tindakan yang perlu dilakukan adalah membangun komunikasi efektif dan sinergitas peran antara pegiat Ojbung, masyarakat Batuputih, pemerintah desa dan pemerintah kabupaten. Masing-masing pihak menjalankan peran sesuai dengan tupoksi masingmasing dan saling mendukung satu sama lain. Pertemuan antar tokoh masyarakat di seluruh wilayah Kabupaten Sumenep harus memperkuat jaringan sosial sehingga social capital terpenuhi dan Ojbung dikenal luas, tidak hanya sebatas di Batuputih, Sumenep saja. Secara infrastruktur, perlu dibangun stadion mini sebagai venue Ojbung, termasuk infrastruktur pendukung, seperti bomestay, fasilitas belanja, dan akses transportasi. Promosi Ojbung telah dilakukan dengan memanfaatkan media cetak (brosur, buku, poster) maupun media elektronik (website dan media sosial). Promosi juga dilakukan melalui pagelaran kesenian, baik di Sumenep maupun di Jakarta dan Bali. Dinas Pariwisata juga mendorong penggunaan dana desa untuk digunakan dalam rangka pengembangan pariwisata karena sektor pariwisata akan menghasilkan secara langsung (direct impact).

Adapun alur perjalanan wisatawan dan layanan yang akan disediakan di area wisata tersebut, antara lain, ketika wisatawan datang berkunjung di Batu Putih, wisatawan akan disambut gapura selamat 
datang di wilayah Kecamatan Batuputih, tepat di wilayah Desa Batuputih Laok. Setiba di Desa Batuputih Laok, wisatawan akan dijamu oleh makanan khas desa dan pemandangan persawahan yang indah. Wisatawan bisa menginap di rumah-rumah penduduk dan akan disambut hangat oleh warga desa.

Arena Ojbung tersedia di lapangan desa yang terletak tepat di tengah-tengah wilayah desa. Sebelum pertandingan Ojbung berlangsung wisatawan akan dihibur dengan tarian pembuka dan iringan musik orkes Okol. Setelah itu, barulah pertandingan Ojbung dimulai dengan peserta yang telah mendaftar terlebih dahulu. Peserta Ojbung adalah petarung antar desa di Kecamatan Batuputih yang sudah terlatih di sanggar Ojbung di desa masing-masing.

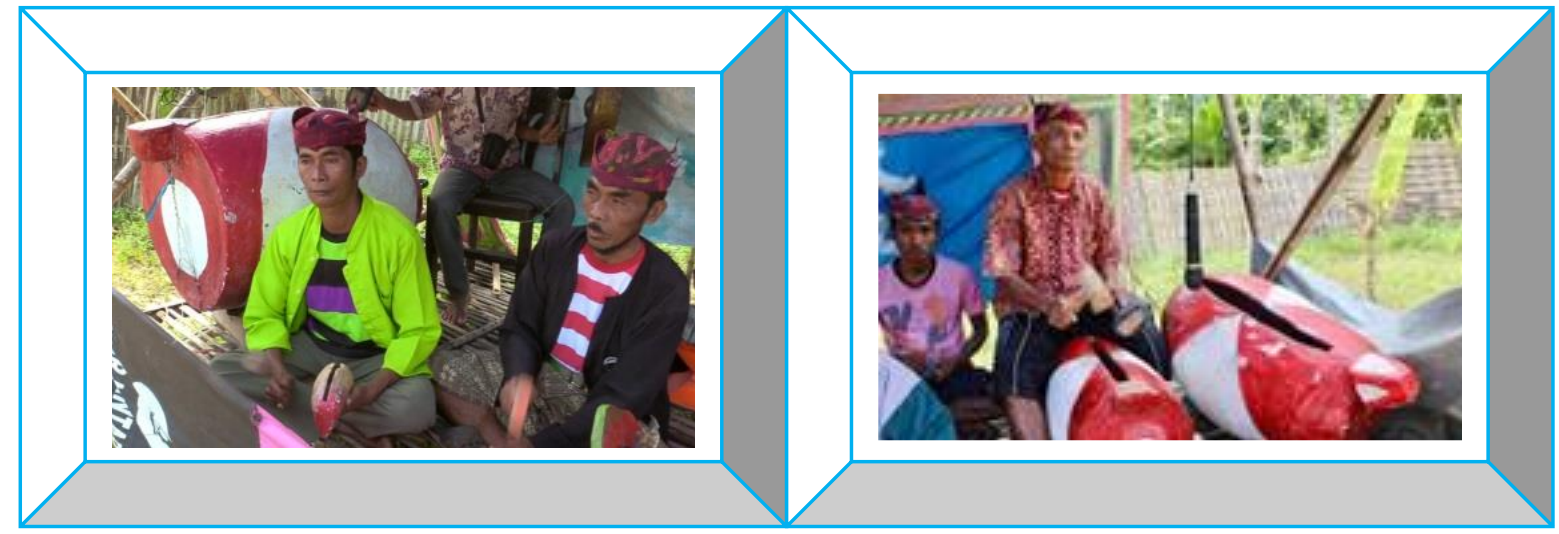

Gambar 1. Orkes Okol sebagai musik pengiring Ojhung

Selepas pertandingan Ojbung, wisatawan dapat mencoba melakukan gerakan Objung dengan syarat dan ketentuan harus didampingi oleh pelatih atau pemain Ojbung yang sudah disiapkan di arena pertandingan. Ketika mencoba melakukan gerakan Ojbung di dalam arena pertandingan, wisatawan akan dibekali alat pukul dari rotan yang disebut lopalo atau kol-pokol; pelindung tangan yang terbuat dari sarung dan diikat di tangan kiri, digunakan untuk menangkis serangan lawan yang disebut tangkes; pelindung pinggang yang disebut amben atau kacot, dan pelindung kepala yang disebut pukot. Apabila wisatawan mengalami cedera atau luka ketika memainkan Ojbung, wisatawan cukup memberikan air yang dicelupkan rotan untuk mengobati luka. Hal ini dipercaya oleh pemain Ojbung bisa mengobati luka. Namun demikian, layanan P3K tetap disiapkan di arena pertandingan Ojbung. Transportasi menuju ke lokasi dan kembali ke pusat kota Sumenep cukup mudah diakses.

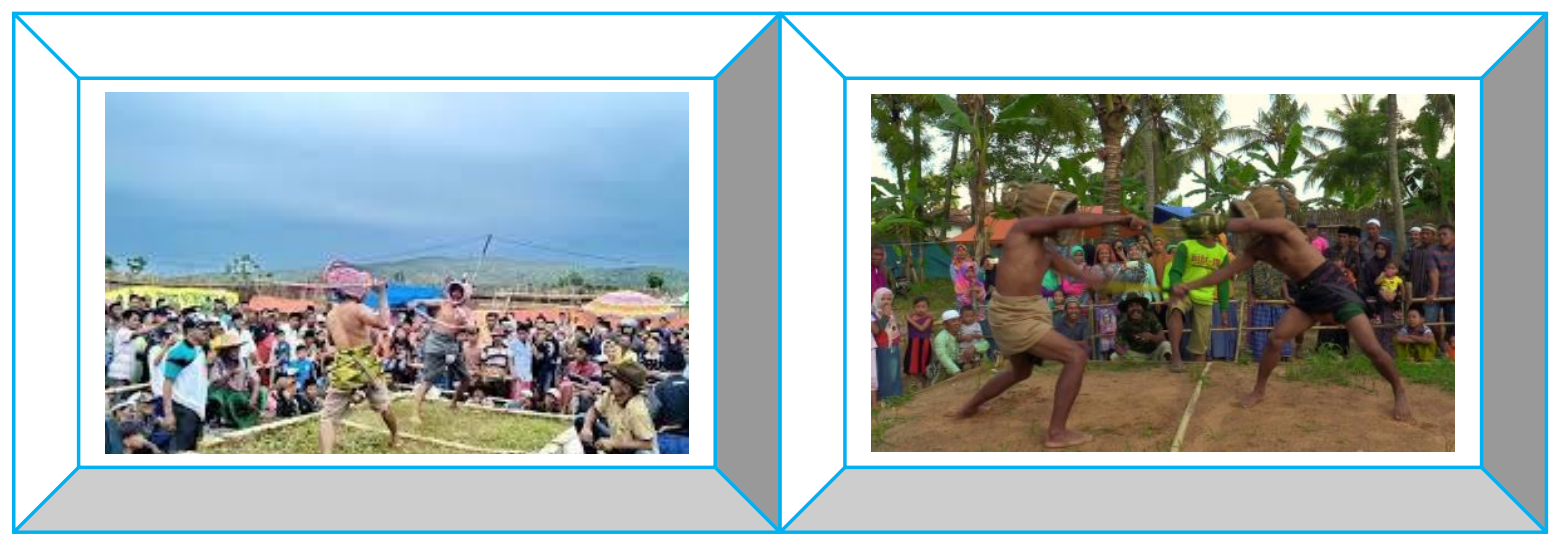

Gambar 2. Pertandingan Ojhung 
Berikut analisis EFAS dan IFAS dalam pengembangan wisata tradisi Ojhung berbasis sport tourism di Kabupaten Sumenep.

\section{Tabel 1. Analisis IFAS}

\begin{tabular}{|c|c|c|c|}
\hline Kunci Faktor Internal & Bobot & Rating (\%) & Skor \\
\hline \multicolumn{4}{|l|}{ (S) Strength/Kekuatan } \\
\hline Ojbung kebudayaan khas Sumenep & 5 & 13,89 & 0,77 \\
\hline Ritual memanggil hujan yang unik dan menarik & 5 & 13,89 & 0,77 \\
\hline Sarana perekat solidaritas sosial & 5 & 13,89 & 0,77 \\
\hline Komitmen menjaga tradisi & 5 & 13,89 & 0,77 \\
\hline Jumlah & 20 & 50,00 & 3,08 \\
\hline \multicolumn{4}{|l|}{ (W) Weakness/Kelemahan } \\
\hline Dukungan anggaran masih terbatas & 4 & 11,76 & 0,69 \\
\hline Kreativitas dan inisiatif pengembangan masih rendah & 3 & 8,82 & 0,52 \\
\hline Infrastruktur belum memadai & 3 & 8,82 & 0,52 \\
\hline Promosi masih sangat terbatas & 3 & 8,82 & 0,52 \\
\hline Kurangnya fokus pemerintah pada pengembangan & 2 & 5,88 & 0,35 \\
\hline Lemahnya regenerasi pemain & 2 & 5,88 & 0,35 \\
\hline Jumlah & 17 & 50,00 & 2,95 \\
\hline Total IFAS & 1 & 100,00 & 0,13 \\
\hline
\end{tabular}

Tabel 2. Analisis EFAS

\begin{tabular}{lccc}
\hline \multicolumn{1}{c}{ Kunci Faktor Eksternal } & Bobot & Rating (\%) & Skor \\
\hline (O) Opportunities/Peluang & & & \\
Branding pariwisata sebagai “Soul of Madura” & 5 & 16,67 & 1,11 \\
Pemanfaatan dana desa untuk pengembangan wisata & 5 & 16,67 & 1,11 \\
Pengembangan sistem pertandingan Ojhung & 4 & 13,33 & 0,89 \\
Daya saing dan daya tarik destinasi wisata lain & 3 & 10 & 0,67 \\
\hline \multicolumn{1}{c}{ Jumlah } & $\mathbf{1 5}$ & $\mathbf{5 0 , 0 0}$ & $\mathbf{3 , 7 8}$ \\
\hline (T) Threats/Ancaman & & & \\
Globalisasi kebudayaan dan olahraga & 4 & 18.18 & 1,65 \\
Perkembangan wisata olahraga di daerah lain & 3 & 13,64 & 1,24 \\
Persepsi negatif wisatawan terhadap Ojbung & 2 & 9,09 & 0,83 \\
\hline \multicolumn{1}{c}{ Jumlah } & $\mathbf{1 1}$ & $\mathbf{5 0 , 0 0}$ & $\mathbf{3 , 7 2}$ \\
\hline \multicolumn{1}{c}{ Total EFAS } & $\mathbf{1 0 0 , 0 0}$ & $\mathbf{0 , 0 6}$ \\
\hline
\end{tabular}

Berdasarkan hasil analisis IFAS dan EFAS (pada Tabel 1 dan Tabel 2), faktor kekuatan total skor sebesar 2,95. Sedangkan pada hasil analisis faktor eksternal, skor pada faktor peluang adalah sebesar 3,78, dan faktor tantangan yaitu 3,72. Dari hasil analisis tersebut, kemudian dapat ditentukan koordinat pada diagram cartesius bertujuan untuk memperoleh strategi yang tepat dalam pengembangan Ojbung sebagai wisata berbasis sport tourism di Kabupaten Sumenep. Koordinat (x) memiliki nilai 0,13, sedangkan koordinat (y) berada pada nilai 0,06, dimana nilai tersebut menunjukkan posisi strategi utama yang merupakan growth strategy. Ojbung Sumenep dapat dikatakan berada pada situasi yang sangat menguntungkan. Faktor kekuatan yang dimiliki Ojbung Sumenep dapat memanfaatkan faktor peluang yang ada untuk menjadi keuntungan bagi pengembangan wisata berbasis sport tourism. Berikut diagram cartesius SWOT. 


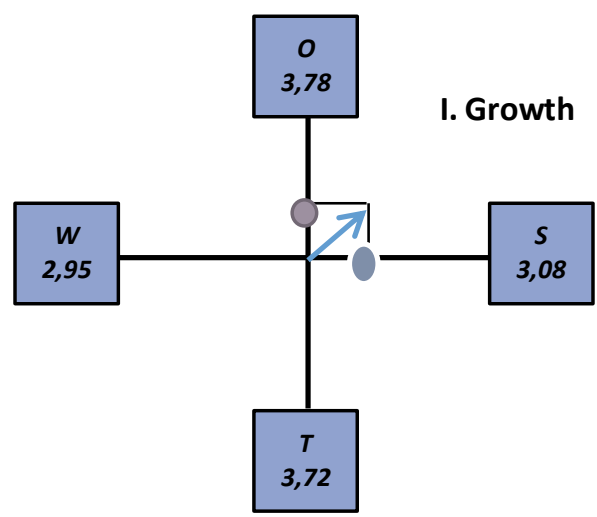

Gambar 3. Diagram Cartesius SWOT

Sumber: Data primer setelah diolah (2019)

\section{Pembahasan}

Seni tradisi Ojbung bisa dikembangkan sebagai destinasi wisata berbasis sport tourism berdasarkan analisis SWOT berikut.

Tabel 3. Analisis SWOT Pengembangan Wisata Tradisi Ojhung di Kabupaten Sumenep

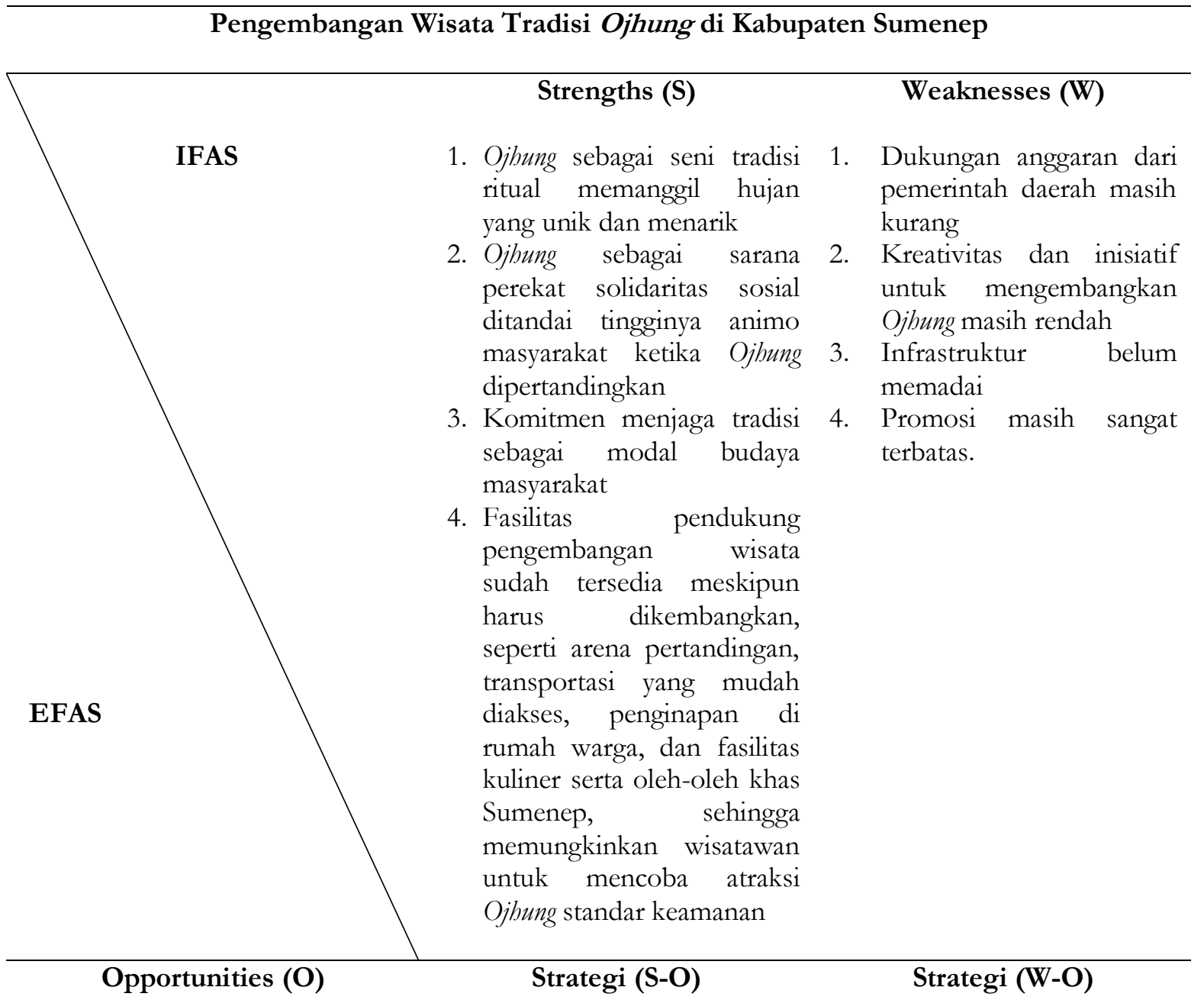

1. Dukungan pemerintah desa 1. Mengembangkan wisata 1. Dukungan regulasi dan 
2. Skill pemain Ojhung sudah mumpuni

3. Ojbung sudah mulai dikenal masyarakat di berbagai wilayah.

4. Potensi wilayah yang bisa dikembangkan menjadi destinasi wisata (sport tourism)

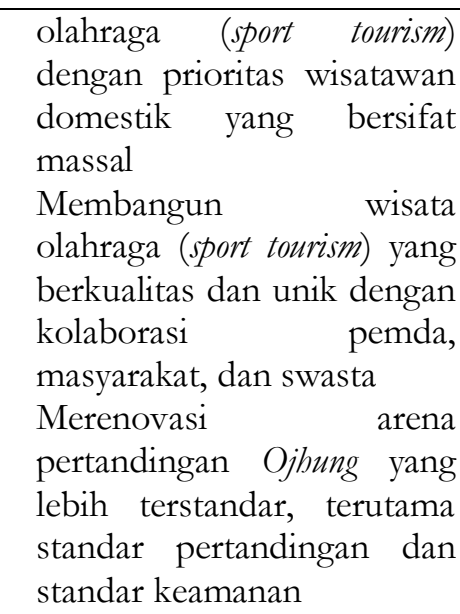

olahraga (sport tourism) dengan prioritas wisatawan domestik yang bersifat olahraga (sport tourism) yang berkualitas dan unik dengan kolaborasi pemda, masyarakat, dan swasta pertandingan Ojbung yang lebih terstandar, terutama standar keamanan infrastruktur pendukung bagi pengembangan wisata olahraga (sport tourism)

2. Menyusun masterplan dengan roadmap yang jelas tentang pengembangan wisata olahraga (sport tourism) untuk memperoleh dukungan pembiayaan dari pusat dan dukungan lintas sektor

3. Memperluas jaringan promosi dengan dukungan teknologi komunikasi (internet)

\section{Threats (T)}

1. Perkembangan wisata berbasis olahraga di daerah lain (mis. Bali) sudah sangat cepat

2. Globalisasi kebudayaan dan olahraga

\section{Strategy (S-T)}

1. Mengembangkan Ojhung sebagai wisata berbasis olahraga (sport tourism) dengan menguatkan tradisi lokal Madura

2. Mengemas paket wisata Ojbung berbasis wisata olahraga secara kreatif dan inovatif

\section{Strategi (W-T)}

1. Mengembangkan Ojhung sebagai wisata berbasis olahraga (sport tourism) yang khas, unik, genuine sesuai kekhasan Madura melalui inovasi yang dilakukan secara intensif

2. Membangun SDM yang kompeten bagi pengelola wisata dan menjalin sinergitas lintas sektor

\section{Strategi pengembangan SO (Strengths-Opportunities)}

Strategi pengembangan SO disusun untuk memaksimalkan seluruh kekuatan yang dimiliki Ojhung Sumenep dengan memanfaatkan peluang sebesar-besarnya. Hasil analisis matriks SWOT menghasilkan 3 (tiga) strategi SO yang dapat diterapkan untuk pengembangan wisata tradisi Ojhung berbasis sport tourism di Kabupaten Sumenep. Strategi SO-1, mengembangkan wisata olahraga (sport tourism) dengan prioritas wisatawan domestik yang bersifat massal. Wisatawan yang mendatangkan banyak wisatawan menjadi daya tarik untuk pengembangan wisata.

Strategi SO-2, membangun wisata olahraga (sport tourism) yang berkualitas dan unik dengan kolaborasi pemda, masyarakat, dan swasta. Pengembangan wisata tradisi Ojbung berbasis sport tourism membutuhkan kolaborasi antara Pemkab Sumenep melalui Dinas Pariwisata, Pemuda dan Olahraga; para investor; dan masyarakat Batu Putih. Sinergi positif dibutuhkan agar wisata Ojhung dapat berkembang dan diminati oleh wisatawan. Strategi SO-3, merenovasi arena pertandingan Ojhung yang lebih terstandar, terutama standar pertandingan dan standar keamanan. Arena pertandingan Ojbung mendesak untuk segera direnovasi sesuai standar sehingga bisa digunakan untuk pertandingan dan semakin menarik para wisatawan.

\section{Strategi pengembangan WO (Weaknesses-Opportunities)}

Strategi pengembangan WO disusun untuk meminimalisir kelemahan melalui peluang yang dimiliki seni tradisi Ojhung. Hasil analisis matriks SWOT menghasilkan 3 (tiga) strategi WO yang dapat diterapkan untuk pengembangan wisata tradisi Ojbung berbasis sport tourism di Kabupaten Sumenep. 
Strategi WO-1, dukungan regulasi dan infrastruktur pendukung bagi pengembangan wisata olahraga (sport tourism). Dukungan regulasi dari pemerintah daerah menjadi penting sebagai payung hukum dalam pengembangan wisata sehingga memiliki pijakan yang jelas dalam implementasi kebijakan. Selain produk hukum, infrastruktur pendukung juga harus disiapkan, seperti akses jalan, promosi dan layanan informasi, bome stay, dan layanan rekreasi.

Strategi WO-2, menyusun masterplan dengan roadmap yang jelas tentang pengembangan wisata olahraga (sport tourism) untuk memperoleh dukungan pembiayaan dari pusat dan dukungan lintas sektor. Masterplan dan roadmap pengembangan perlu disusun untuk mengetahui arah pengembangan wisata seni tradisi Ojbung dalam jangka pendek, menengah, dan jangka panjang, sehingga tujuan pengembangan menjadi jelas dan terukur. Strategi WO-3, memperluas jaringan promosi dengan dukungan teknologi komunikasi (internet). Promosi menjadi sangat penting untuk menarik jumlah wisatawan. Perkembangan teknologi informasi dan komunikasi sangat memungkinkan untuk mengembangkan konten dan desain media promosi yang lebih kreatif, inovatif dan kekinian. Promosi kreatif akan menggerakkan generasi milenial untuk tertarik pada wisata budaya, termasuk Ojhung.

\section{Strategi pengembangan ST (Strengths-Threats)}

Strategi pengembangan ST disusun untuk meminimalisir ancaman dengan memaksimalkan kekuatan yang dimiliki seni tradisi Ojbung. Hasil analisis matriks SWOT menghasilkan 2 (dua) strategi ST yang dapat diterapkan untuk pengembangan wisata tradisi Ojbung berbasis sport tourism di Kabupaten Sumenep. Strategi ST-1, mengembangkan Ojbung sebagai wisata berbasis olahraga (sport tourism) dengan menguatkan tradisi lokal Madura. Ojbung merupakan seni tradisi masyarakat lokal Madura, sehingga kebudayaan Madura yang bercirikan pantang menyerah dan jiwa resistensi terasa sangat kental pada tradisi Ojhung. Apabila seni tradisi Ojhung maka akan semakin menguatkan kebudayaan Madura.

Strategi ST-2, mengemas paket wisata Ojhung berbasis wisata olahraga secara kreatif dan inovatif. Produk yang laku keras sangat ditentukan oleh dimensi pengemasan yang menarik. Oleh karena itu, pengembangan seni tradisi Ojbung harus dikemas lebih kreatif dan inovatif agar memiliki daya magnet yang kuat untuk menarik animo wisatawan berkunjung ke Sumenep.

\section{Strategi pengembangan WT (Weakness-Threats)}

Strategi pengembangan W'T disusun untuk meminimalkan kelemahan serta menghindari ancaman yang dimiliki seni tradisi Ojbung. Hasil analisis Matriks SWOT menghasilkan 2 (dua) strategi WT yang dapat diterapkan untuk pengembangan wisata tradisi Ojhung berbasis sport tourism di Kabupaten Sumenep. Strategi WT-1, mengembangkan Ojbung sebagai wisata berbasis olahraga (sport tourism) yang khas, unik, genuine sesuai kekhasan Madura melalui inovasi yang dilakukan secara intensif. Ojbung merupakan seni tradisi yang khas bagi masyarakat Sumenep karena digunakan sebagai instrumentasi memanggil hujan. Kekhasan dan keunikan tradisi Ojbung merupakan modal untuk dikembangkan sebagai destinasi wisata

Strategi WT-2, membangun SDM yang kompeten bagi pengelola wisata dan menjalin sinergitas lintas sektor. Pengembangan tradisi Ojbung sebagai wisata berbasis sport tourism membutuhkan kerjasama antar lintas sektor terkait, baik dari Dinas Pariwisata, Pemuda dan Olahraga, maupun OPD lain yang terkait, seperti Dinas Koperasi dan UMKM, Dinas Perhubungan, Dinas Bina Marga, termasuk sektor lain, seperti swasta, lembaga masyarakat, pemerintah desa, dan perguruan tinggi. 


\section{Simpulan dan Rekomendasi}

Berdasarkan hasil analisis SWOT menunjukkan bahwa strategi yang harus diterapkan dalam pengembangan Ojbung sebagai sport tourism. Pertama, strategi pengembangan tradisi Ojbung, melalui perencanaan Ojbung sebagai event unggulan dalam Kalender Event Sumenep; dan pengadaan sanggar Ojbung. Kedua, strategi pengembangan promosi, melalui promosi oleh Dinas Kebudayaan Pariwisata Pemuda dan Olahraga Kabupaten Sumenep; kerjasama dengan Biro Perjalanan Wisata; dan optimalisasi Tourist Information Center (TIC). Ketiga, strategi pengembangan pariwisata berkelanjutan, melalui peningkatan kualitas lingkungan; peningkatan kualitas kehidupan sosial budaya masyarakat lokal; dan peningkatan perekonomian untuk masyarakat. Keempat, strategi pengembangan dan peningkatan kualitas SDM melalui pelatihan pengelolaan pariwisata

Pemerintah Kabupaten Sumenep secara konsisten harus terus mengembangkan seni tradisi Ojhung sebagai destinasi wisata berbasis olahraga (sport tourism), melalui kerjasama lintas sektor, promosi dan kemasan wisata secara lebih menarik, kreatif dan inovatif sehingga mampu menggerakkan wisatawan untuk mengunjungi Kabupaten Sumenep, terutama di Batu Putih sebagai pusat tradisi Ojbung.

\section{Ucapan Terima Kasih:}

Terima kasih kepada Kementerian Riset, Teknologi dan Pendidikan Tinggi yang telah membiayai penelitian ini melalui Program Kreativitas Mahasiswa (PKM) tahun anggaran 2019.

\section{Daftar Pustaka:}

Abbas, A. (2017). Kesenian Ojhung Dalam Tradisi Sedekah Bumi Di Desa Bunbarat Kecamatan Rubaru Kabupaten Sumenep Tahun 1960-2005. Avatara, 5(1).

Albrecht, J.N. (2010). Challenges in Tourism Strategy Implementation in Peripheral Destinations The Case of Stewart Island, New Zealand. Tourism and Hospitality Planning \& Development, 7(2): 91-110.

Anggita, G.M., Mukarromah, S. B., \& Ali, M. A. (2018). Eksistensi Permainan Tradisional sebagai Warisan Budaya Bangsa. JOSS AE: Journal of Sport Science and Education, 3(2), 55.

Astuti, M.T., \& Noor, A.A. (2016). Daya Tarik Morotai Sebagai Destinasi Wisata Sejarah dan Bahari. Jurnal Kepariwisataan Indonesia, 11(1), 25-45.

Cahyo, S. (2018). Pariwisata Potensi Ekonomi Unggulan Sumenep. Retrieved June 19, 2019, from www.koran-jakarta.com website: http://www.koran-jakarta.com/pariwisata-potensi-ekonomiunggulan-sumenep/

Di Palma, D., Tafuri, D., Ascione, A., \& Raiola, G. (2018). Social, Tourism and Educational development through Sport. Journal of Physical Education and Sport, 18(1), 473-478.

Gibson, H.J (2018). Active Sport Tourism: Who Participates?, Leisure Studies, 17(2), 155-170.

Hani, T. (2007). Persepsi Wisatawan Terhadap Mepantigan Sebagai Pariwisata Alternatif di Pondok Mepantigan di Gianyar Bali. Skripsi, Sekolah Tinggi Pariwisata Bali Internasional.

Honari, H., Goudarzi, M., Heidari, A., \& Emami, A. (2010). A comparison of the viewpoints of tourists, interested managers and cultural heritage organization managers regarding sport tourism-driven job and income creation in Mazandaran-Iran. Procedia-Social and Behavioral 
Sciences, 2(2), 5659-5663.

Maknuna, L.L., Mustamar, S. dan Ningsih, S. (2013). Mantra Dalam Tradisi Pemanggil Hujan di Situbondo: Kajian Struktur, Formula, dan Fungsi. Publika Budaya, 1(1): 1-15.

Nur, H. (2013). Membangun karakter anak melalui permainan anak tradisional. Jurnal Pendidikan Karakter, (1).

Pradana, F.G.A., Hidayat, N., Juniarisca, D.L., \& Imron, A. (2019). The Potential of" Ojhung" Tradition Art as Sports Tourism in Sumenep District. Social Sciences, Humanities and Education Conference (SoSHEC 2019). Atlantis Press.

Rahman, dkk. (2019). Strategi Pelestarian Budaya Ojbung Madura di Era Global. Performance: Jurnal Bisnis dan Akuntansi, 9(2), 127-139.

Rosita, R. (2017). Upaya Dinas Pariwisata, Kebudayaan, Pemuda dan Olahraga Kabupaten Sumenep dalam Meningkatkan Pelayanan Publik terhadap Wisatawan (Studi Kasus: Pulau Gili Labak, Kabupaten Sumenep Madura). Kebijakan Dan Manajemen Publik, 5(3), 1-8.

Samiarta, I.G., \& Mahagangga, I.G A.O. (2016). Perkembangan Desa Wisata di Kabupaten Badung (Studi Kasus Desa Wisata Baha). Jurnal Destinasi Pariwisata, 4(2), 114-117.

Sugiyono, P. (2010). Dr. Metode Penelitian Pendidikan: Pendekatan Kuantitatif, Kualitatif dan ReDD Cet.

Sutawa, G.K. (2012). Issues on Bali tourism development and community empowerment to support sustainable tourism development. Procedia Economics and Finance, 4(1), 413-422.

UU RI. (2005). Undang-Undang Nomor 3 Tabun 2005 tentang Sistem Keolahragaan Nasional.

Wardiyanta. (2010). Metode penelitian pariwisata. Yogyakarta: Andi.

Zulkarnain, H.I. (2004). Aneka ragam kesenian Sumenep. Dinas Pariwisata dan Kebudayaan, Kabupaten Sumenep. 